\title{
Isolation and characterization of Vibrio parahaemolyticus from seafoods along the southwest coast of India
}

\author{
Rekha D. Chakraborty $\cdot$ P. K. Surendran • \\ Toms C. Joseph
}

Received: 30 December 2007 / Accepted: 22 February 2008/Published online: 4 March 2008

(C) Springer Science+Business Media B.V. 2008

\begin{abstract}
The work was aimed to study the microbial quality of the seafood sold in the domestic markets and incidence of Vibrio parahaemolyticus. Samples comprising of shellfish, finfish, and cephalopods were collected from various fish markets in and around Cochin. Presumed V. parahaemolyticus were identified by standard biochemical tests, and further confirmed by polymerase chain reaction targeting species-specific $t l$ gene $(450 \mathrm{bp})$. About $81 \%$ of the samples were found to exceed the limits specified for total plate count while total presumptive $V$. parahaemolyticus count was above the limit in $71 \%$ of the samples ranging from $5.5 \times 10^{5}$ to $9.7 \times 10^{7}$ and $0.31 \times 10^{2}$ to $7.8 \times 10^{6} \mathrm{cfu} / \mathrm{g}$, respectively. Pathogenicity of the identified isolates was confirmed by Kanagawa phenomenon and urease activity. A total of $10 \%$ of the isolates exhibited weak haemolysis on Wagatsuma agar, and $1 \%$ of the isolates showed urease activity using Christensen's urea agar. Random amplified polymorphic DNA analysis revealed two major clusters based on the species rather than seasonality. The gel pattern revealed $8-10$ bands ranging from 0.45 to $3.0 \mathrm{~kb}$. Antibiogram results revealed $85 \%$ of the strains sensitive to chloramphenicol and nitrofurantoin. Multiple antibiotic resistance index was found to be 0.4 thus suggesting the risk potential involved in consuming
\end{abstract}

R. D. Chakraborty $(\varangle) \cdot$ P. K. Surendran · T. C. Joseph Microbiology Fermentation and Biotechnology Division, Central Institute of Fisheries Technology, Matsyapuri, Cochin, Kerala, India

e-mail: rekhadevi76@yahoo.com

Present Address:

R. D. Chakraborty

Division of Crustacean Fisheries, Central Marine Fisheries

Research Institute, Ernakulam North P. O, P. B. No. 1603,

Cochin, Kerala 682018, India seafoods. The present study has clearly demonstrated the need to adopt seafood safety measures for the products meant for human consumption.

Keywords Vibrio parahaemolyticus $\cdot \mathrm{PCR} \cdot t l \cdot$ Antibiotics · RAPD

\section{Introduction}

Global production of fish and fishery products has more than doubled since 1970, reflecting an increase in capture, and in particular aquaculture production (Delgado et al. 2003). Cochin, the economic capital of Kerala is a major fish-landing center in south west coast of India accounting for $90 \%$ of statewide exports. Vibrios of seafood origin have attracted increasing attention from time to time as it is found to be one of the most important causes of human food poisoning. Earlier reports revealed food poisoning due to the consumption of seafood contaminated with Vibrio species, particularly Vibrio parahaemolyticus (Wong et al. 2000). The incidence of this bacterium increased considerably during recent years in US, Japan and Korea (Lee et al. 2001), and in India it was reported to be doubled in the last 5 years (Chowdhury et al. 2000). The organism has been well recognized as the causative agent of gastroenteritis, wound infections, and septicemia through the consumption of contaminated seafoods (Fujino et al. 1953). Although $V$. parahaemolyticus forms the common cause of gastroenteritis transmitted by contaminated seafood consumption, the true incidence was not known probably due to underreporting of cases and lack of proper study.

Epidemiological studies revealed an association between the Kanagawa phenomenon (KP) positive and 
gastroenteritis (Okuda et al. 1997). In the 1980s few gastroenteritis cases were reported from the KP negative $V$. parahaemolyticus isolates, which led to the discovery of the thermostabele direct haemolysin (TDH)-related haemolysin, TRH (Hervio-Heath et al. 2002). Studies revealed the TDH and TRH, encoded by the phenotypic tests viz., $\mathrm{KP}$ and urea hydrolysis respectively, were considered as phenotypic markers for pathogenicity (Kaysner et al. 1994). A separate thermolabile hemolysin gene ( $t l$ gene) was found to be present in all the strains of V. parahaemolyticus (Taniguchi et al. 1986) irrespective of their ability to produce TDH or TRH. In the present study $t l$ gene, specific to $V$. parahaemolyticus has been applied for definitive identification of $V$. parahaemolyticus isolates.

A DNA-based typing technique that is frequently used to generate strain-specific fingerprinting (Hulton et al. 1991), relies on the polymerase chain reaction (PCR) and primers directed to specific nucleotide sequences. Typing methods viz., pulsed-field gel electrophoresis (Wong et al. 1996), ribotyping (Wong et al. 1999a), and random amplified polymorphic DNA (RAPD) analysis (Wong et al. 1999b) were developed to study the genetic relationships between strains and species of microorganisms (Oakey et al. 1998). Compared with all these methods, RAPD analysis has its merits of being consuming less labor and time. RAPD fingerprinting analysis is a commonly used method in PCR for typing and differentiation of bacteria.

Antibiotics and other chemotherapeutic agents are commonly used in fish farms either as feed additives or immersion baths to achieve either prophylaxis or therapy. As antibiotics were used for feeding animals and for treatment of patients, more drug resistance characteristics were detected in food borne pathogens (Barza 2002). The rapid increase of drug resistant pathogenic bacteria during the recent years has rendered many known antibiotics ineffective. Although the majority of shrimp exported from Kerala are from marine capture, for which antibiotics are not normally an issue, residues have been detected through border checks in the EU even in marine captured seafoods forcing controls on antibiotics onto the agenda of all exporters.

Earlier studies carried out at Cochin were based on the conventional methods used phenotypic assays and biochemical tests to identify virulent strains of $V$. parahaemolyticus, requiring several days for confirmation of the pathogen (Sanjeev and Stephen 1992). In the present study PCR that was found to be rapid and sensitive was used for the detection of this pathogen. The study was aimed to investigate the incidence of $V$. parahaemolyticus in seafoods marketed from this area and to detect the presence of pathogenic isolates, antibiotic resistance, and genetic relatedness among the isolates.

\section{Materials and methods}

Sample collection, processing and enrichment

Samples were collected from markets located in and around Cochin for studying the incidence of $V$. parahaemolyticus in various seafoods at regular intervals from October 2005 to September 2006. Finfish samples included Etroplus suratensis, Pampus argentius, Megalaspis cordyla, Oreochromis mossambicus, Mugil cephalus, Sardinella longipes, and Labeo rohita. Shellfishes consisted of Metapenaeus dobsoni, Metapenaeus affinis, Macrobrachium rosenbergii, Penaeus monodon, Fenneropenaeus indicus, Scylla serrata, Parapenaeopsis stylifera, and Panulirus homarus. Cephalopod samples included Sepia pharonis and Loligo duvacelli. All the samples were processed under sterile conditions within $2 \mathrm{~h}$ of collection. Bacteriological analysis was performed with three samples separately, and average counts were taken. The samples $(25 \mathrm{~g})$ were homogenized with alkaline peptone water (APW) broth $(225 \mathrm{ml})$ in a sterile polythene stomacher bag (Stomacher 400 Seaward medicals, UK) at $230 \mathrm{rpm}$ for $1 \mathrm{~min}$, and enriched in APW broth for 18-24 h.

\section{Isolation and identification of V. parahaemolyticus}

After $18-24 \mathrm{~h}$ of incubation in APW broth $(0.5 \mathrm{ml})$ was aseptically pipetted into thiosulphate citrate bilesalt sucrose agar (TCBS) and tryptone glucose agar (TGA) plates previously preset and dried $\left(56^{\circ} \mathrm{C}, 45 \mathrm{~min}\right)$. The TCBS and TGA plates were incubated at $37^{\circ} \mathrm{C}$ for $24-30 \mathrm{~h}$ and $37^{\circ} \mathrm{C}$ for $24-48 \mathrm{~h}$, respectively. TGA plates giving colony counts ranging between 30 and 300 were counted and recorded as total plate count (TPC). About 3-4 typical colonies having green or bluish green color with dark blue or green centre measuring about $3-5 \mathrm{~mm}$ were picked from TCBS plate, and each one was inoculated into sterile sucrose broth supplemented with $\mathrm{NaCl}(3 \% \mathrm{w} / \mathrm{v})$. Sucrose non-fermenting colonies were streaked onto sterile tryptone soy agar slants (TSA) supplemented with $\mathrm{NaCl}(3 \% \mathrm{w} / \mathrm{v})$, and maintained at room temperature for further identification. Halophilism tests were performed using tryptone broth with different concentrations of $\mathrm{NaCl}(0,3,6,8$, and $10 \% \mathrm{w} / \mathrm{v})$. Additional characterization tests for the identification of $V$. parahaemolyticus namely, Gram staining, catalase, cytochrome oxidase, triple sugar iron, lysine iron agar, arginine dehydrolase, lysine and ornithine decarboxylase, and O/129 susceptibility were performed. Tests for glucose oxidationfermentation were carried out using Hugh-Leifson broth, and arabinose, lactose, mannitol, mannose, salicin, cellobiose, and inositol fermentation tests were also performed following standard procedure (USFDA 2001). All the media were supplemented with $\mathrm{NaCl}(3 \%$ w/v) unless otherwise specified. Colonies that gave typical colony characteristics 
were picked up and confirmed by Kanagawa (Wagatsuma 1968) and urease tests (Andrews and Hammack 2001). The presumed positive cultures were confirmed using RAPID Hi-Vibrio $^{\text {TM }}$ identification kit (KB007, Himedia, India).

Kaneko and Colwell (1975) suggested that all the colonies growing on TCBS could be regarded as presumptive vibrios (PV) and colonies that appear to be typical (green colonies with dark blue or green centre measuring about 3-5 mm) as $V$. parahaemolyticus were considered as presumptive $V$. parahaemolyticus (PVP). A similar criterion was used in this study for the enumeration of PV and PVP counts in the samples.

Detection of the phenotypic markers for pathogenicity

The phenotypic test for the production of TDH from $V$. parahaemolyticus isolates was studied by testing the KP on Wagatsuma agar (Elliot et al. 1992). Briefly the test strains were inoculated and incubated at $37^{\circ} \mathrm{C}$. The production of $\beta$-haemolysis zone around the colonies within $24 \mathrm{~h}$ was judged as KP positive. The phenotypic marker for the production of TRH was studied by testing urease activity using Christensen's urea agar (Andrews and Hammack 2001).

\section{Antibiotic sensitivity test}

Antibiotic sensitivity of the $V$. parahaemolyticus cultures was determined by the standard disk diffusion method (Bauer et al. 1966). Antibiotic discs (Himedia, India) were placed aseptically on the Mueller-Hinton agar plates (three replicates) pre-inoculated with the test culture. The discs were placed at $15 \mathrm{~mm}$ away from the edge of the plates, at equal distance, and sufficiently separated from each other to avoid overlapping of the zone of inhibition. The plates were incubated at $37^{\circ} \mathrm{C}$ for $18-24 \mathrm{~h}$, and the size of inhibition zone was recorded both in test and control isolates. The antibiotics evaluated were polymixin-B, gentamycin, tetracycline, nalidixic acid, chloramphenicols, nitrofurantoin, and trimethoprim. The multiple antibiotic resistance (MAR) index was determined as the ratio between the number of antibiotics for which the organism is resistant and the total number of antibiotics used.

\section{Preparation of bacterial lysate for PCR assay}

Bacterial lysate was prepared following established procedure (Karunasagar et al. 1996). The biochemically identified isolate was streaked on TSA plates and the isolated colony was inoculated in the Luria Bertane (LB) broth supplemented with $\mathrm{NaCl}(2 \% \mathrm{w} / \mathrm{v})$, and incubated at $37^{\circ} \mathrm{C}$ under shaking $(120 \mathrm{rpm})$ for $16-18 \mathrm{~h}$. The culture broth was centrifuged $\left(10,000 \mathrm{rpm}, 4^{\circ} \mathrm{C}, 1 \mathrm{~min} ; 5804 \mathrm{R}\right.$,
Eppendorf, Germany) to obtain the pellet, which was washed with normal saline $(0.8 \% \mathrm{NaCl} w / v)$, and re-suspended with DNA-free sterile distilled water $(200 \mu \mathrm{l})$. The resulting suspension was heated at $98 \pm 2^{\circ} \mathrm{C}$ for $15-20 \mathrm{~min}$ in a water bath to lyse the cells, and release the DNA. The lysate was clarified by centrifugation $(10,000 \mathrm{rpm}$, $\left.4^{\circ} \mathrm{C}, 5 \mathrm{~min}\right)$, and the supernatant was stored $\left(-20^{\circ} \mathrm{C}\right)$ until further use.

The PCR targeting species-specific $t l$ gene of $V$. parahaemolyticus was performed (Bej et al. 1999) in a thermocycler (Eppendorf Mastercycler, Germany) using a primer pair (5' AAA GCG GAT TAT GCA GAA GCA CTG $3^{\prime}$ and $5^{\prime}$ GCT ACT TTC TAG CAT TTT CTC TGC $3^{\prime}$ ) to detect the gene.

\section{Extraction and purification of chromosomal DNA}

Genomic DNA from V. parahaemolyticus isolates was extracted following the method of Ausubel et al. (1987). Briefly, a colony with typical characteristics was picked from the TCBS plate and was grown overnight in LB broth containing $\mathrm{NaCl}(3 \% \mathrm{w} / \mathrm{v})$ and incubated at $37^{\circ} \mathrm{C}$ under shaking $(120 \mathrm{rpm})$ for $16-18 \mathrm{~h}$. DNA was extracted from culture in exponential phase of growth of the organism by giving a wash with normal saline $(\mathrm{NaCl} 0.8 \% \mathrm{w} / \mathrm{v})$, followed by resuspending in TE buffer $(10 \mathrm{mM}$ Tris-Cl, $1 \mathrm{mM} \mathrm{Na}{ }_{2}$ EDTA, pH 8.0). Alkaline lysis was performed with sodium dodecyl sulfate $(20 \% \mathrm{w} / \mathrm{v})$ (SDS, SRL India), and proteinase K $(20 \mathrm{mg} / \mathrm{ml}$, Sigma, Aldrich Chemical, USA). After $1 \mathrm{~h}$ of incubation at $37^{\circ} \mathrm{C}, \mathrm{NaCl}(5 \mathrm{M})$ was added along with cetyl trimethyl ammonium bromide/ $\mathrm{NaCl}$ solution to complex with the polysaccharides. DNA was purified from proteins and other cellular constituents using an equal volume of chloroform-isoamyl alcohol (24:1 v/v) followed by centrifugation $(10,000 \mathrm{~g})$ for $5 \mathrm{~min}$. Further purification of the supernatant was achieved by adding an equal volume of phenol-chloroform-isoamyl alcohol $(25: 24: 1 \mathrm{v} / \mathrm{v})$ to the supernatant, followed by centrifugation $(10,000 g)$. Sodium acetate (0.1 volume, $3 \mathrm{M}, \mathrm{pH}$ 5.2) was added to the supernatant to chelate the salts followed by chilled absolute alcohol (2 volume) to precipitate the DNA. The sample $(0.2 \mathrm{ml})$ was centrifuged $(12,000 \mathrm{~g})$ for $10 \mathrm{~min}$ and the DNA pellet was washed once with cold ethanol $(70 \% \mathrm{v} / \mathrm{v})$ before being dried under vacuum. The purified DNA was resuspended in TE buffer and stored at $-20^{\circ} \mathrm{C}$ until further use.

PCR conditions for the detection of $t l$ gene

PCR amplification was optimized in a total reaction volume of $25 \mu \mathrm{l}$ consisting of sterile Milli Q water $(13.5 \mu \mathrm{l}), 10 \times \mathrm{PCR}$ buffer $(2.5 \mu \mathrm{l})$, primer $(1.5 \mu \mathrm{l})$, dNTP mix $(0.5 \mu \mathrm{l}, 200 \mathrm{mM})$, template $(5 \mu \mathrm{l})$, and Taq DNA polymerase $(0.5 \mu \mathrm{l})$. The 
components were mixed well and the PCR amplification of the target sequence was arranged in a thermocycler (Eppendorf Mastercycler, Germany), and programmed for 30 cycles of amplification. Each cycle consisted of three step reactions i.e., initial denaturation $\left(94^{\circ} \mathrm{C}, 3 \mathrm{~min}\right)$ followed by 30 cycles of denaturation $\left(94^{\circ} \mathrm{C}, 1 \mathrm{~min}\right)$, annealing $\left(60^{\circ} \mathrm{C}, 1 \mathrm{~min}\right)$ and extension $\left(72^{\circ} \mathrm{C}, 1 \mathrm{~min}\right)$ followed by final extension $\left(72^{\circ} \mathrm{C}\right.$, $5 \mathrm{~min})$.

\section{RAPD-PCR conditions}

RAPD analysis was carried out using the 10-nucleotide primer, 5'CAG GCG CAC A3' (Wong 2003). PCR reaction conditions have been optimized for important parameters such as annealing temperature and concentrations of $\mathrm{MgCl}_{2}$, template DNA, Taq DNA polymerase, dNTPs and primer. The PCR reaction mixture comprised of $2.0 \mu \mathrm{l}$ of $10 \times$ buffer (100 mM Tris- $\mathrm{HCl} \mathrm{pH} 8.3,500 \mathrm{mM} \mathrm{KCl,} 20 \mathrm{mM} \mathrm{MgCl}_{2}$ and $0.001 \%$ gelatin), dNTP mix $(1.0 \mu \mathrm{l}, 200 \mathrm{mM}), 0.5 \mu \mathrm{l}$ of Taq DNA polymerase (2.5 units, Fermentas $5 \mathrm{U} / \mu \mathrm{l})$, primer (30 pM), DNA template $(1 \mu \mathrm{l})$, and an additional $3.0 \mu \mathrm{l}$ of $\mathrm{MgCl}_{2}(25 \mathrm{mM})$ adjusted to a reaction volume of $25 \mu \mathrm{l}$ with an appropriate volume of sterile Milli Q water. Amplifications were performed on a thermocycler (Eppendorf Mastercycler, Germany), which was programmed for an initial denaturation $\left(94^{\circ} \mathrm{C}, 5 \mathrm{~min}\right)$ followed by 45 cycles of denaturation $\left(94^{\circ} \mathrm{C}, 1 \mathrm{~min}\right)$ and primer annealing $\left(38^{\circ} \mathrm{C}\right.$, $1 \mathrm{~min}, 30 \mathrm{~s})$. The extension was carried out at $72^{\circ} \mathrm{C}(2 \mathrm{~min}$, $30 \mathrm{sec})$ followed by final extension at $72^{\circ} \mathrm{C}(10 \mathrm{~min})$.

The PCR products were resolved on agarose $(1.5 \% \mathrm{w} / \mathrm{v})$ gel electrophoresis. The gel was stained with ethidium bromide $(0.5 \mathrm{mg} / \mathrm{ml})$ and visualized under a UV transilluminator (Alpha Imager, Innotech Corporation, USA). GeneRuler $^{\mathrm{TM}} 100$ bpDNA Ladder (MBI Fermentas, USA) was used as a molecular size marker.

\section{Cluster analysis}

Similarity matrix was built for $V$. parahaemolyticus isolates using Pearson's correlation co-efficient. Cluster analysis was performed and dendrogram was constructed using the data matrix of all the strains isolated from market samples based on unweighted pair-group method with arithmetic means (UPGMA) (Sneath and Sokal 1973) using the Gel Compar II software, version 4.0 (Applied-Maths, St-Martens-Latem, Belgium).

\section{Results}

About $88 \%$ of the shellfish samples have exceeded the limit specified for TPC (USFDA 2001) ranging from $1.1 \times 10^{6}$ to $4.74 \times 10^{7} \mathrm{cfu} / \mathrm{g}$, and in the remaining $12 \%$ of the samples,
TPC values ranged from $1.5 \times 10^{5}$ to $3.96 \times 10^{5} \mathrm{cfu} / \mathrm{g}$. Total presumptive vibrio count (TPVC) was found to be in the range of $0.95 \times 10^{2}$ to $5.7 \times 10^{5}$, and total presumptive $V$. parahaemolyticus count (TPVPC) was found to cross the limit (ICMSF 1986) in $64 \%$ of the samples $\left(1.21 \times 10^{3}\right.$ to $\left.4.4 \times 10^{5} \mathrm{cfu} / \mathrm{g}\right)$. The incidence of $V$. parahaemolyticus was found to be $64 \%$, highest being in summer months (February to May) as evident from Table 1.

About $67 \%$ of the finfish samples have exceeded the limit specified for TPC (USFDA 2001) ranging from $5.5 \times 10^{5}$ to $4.5 \times 10^{7} \mathrm{cfu} / \mathrm{g}$, and in the remaining samples $(33 \%)$ TPC was in the range of $2.6 \times 10^{4}$ to $7.2 \times 10^{4} \mathrm{cfu} / \mathrm{g}$ (Table 1$)$. TPVC was found to be in the range of $2.73 \times 10^{2}$ to $4.2 \times 10^{4}$ and TPVPC was above the limit (ICMSF 1986) in $75 \%$ of the samples $\left(1.05 \times 10^{3}\right.$ to $\left.3.6 \times 10^{4} \mathrm{cfu} / \mathrm{g}\right)$. Total incidence of $V$. parahaemolyticus in finfish samples was found to be $42 \%$, the highest being found during summer months.

About $80 \%$ of the cephalopod samples have exceeded the limit specified for TPC (USFDA 2001) ranging from $1.5 \times 10^{6}$ to $9 \times 10^{7} \mathrm{cfu} / \mathrm{g}$ and in the remaining $20 \%$ of the samples TPC was found to be from $2.0 \times 10^{5}$ to $3.2 \times 10^{5} \mathrm{cfu} / \mathrm{g}$. TPVC was found to be in the range of $7.8 \times 10^{3}$ to $9.2 \times 10^{6}$ and TPVPC was recorded above the specified limit (ICMSF 1986) in all the samples $\left(3.6 \times 10^{3}\right.$ to $\left.7.8 \times 10^{6} \mathrm{cfu} / \mathrm{g}\right)$, whereas the incidence of $V$. parahaemolyticus was found to be $42 \%$. The results revealed $80 \%$ of cephalopod samples collected from Cochin markets were of very poor quality considering the TPC limits (Table 1).

None of the isolates exhibited $\beta$-haemolysis while $10 \%$ of the isolates exhibited $\alpha$-haemolysis on Wagatsuma agar, and $1 \%$ of the colonies exhibited urease activity on urea agar slants of which one was isolated from the inshore shrimp, Metapenaeus dobsoni and the other from M. affinis. PCR analysis was carried out by targeting species-specific $t l$ gene (450 bp) for all the $V$. parahaemolyticus isolates that included both positive (MTCC 451) and negative controls. All the isolates that were indentified as $V$. parahaemolyticus by biochemical tests were further confirmed by PCR were found to amplify the $t l$ gene (Fig. 1).

If more than $70 \%$ of the isolates exhibits resistance to a particular antibiotic, then such antibiotic was taken into consideration for the calculation of MAR. In the present study MAR was found to be 0.4 . About $100 \%$ sensitivity was noticied towards tetracycline, nalidixic acid followed by chloramphenicol, trimethoprim, and nitrofurantoin (Table 2).

$V$. parahaemolyticus isolates were analyzed by RAPD analysis revealing two major clusters, namely $\mathrm{A}$ and $\mathrm{B}$ based on the species rather than seasonality of sample collection. Group A included $40 \%$ of cultures isolated from shrimps, clustered with group B at $\mathrm{S} \leq 20 \%$ (S, similarity 


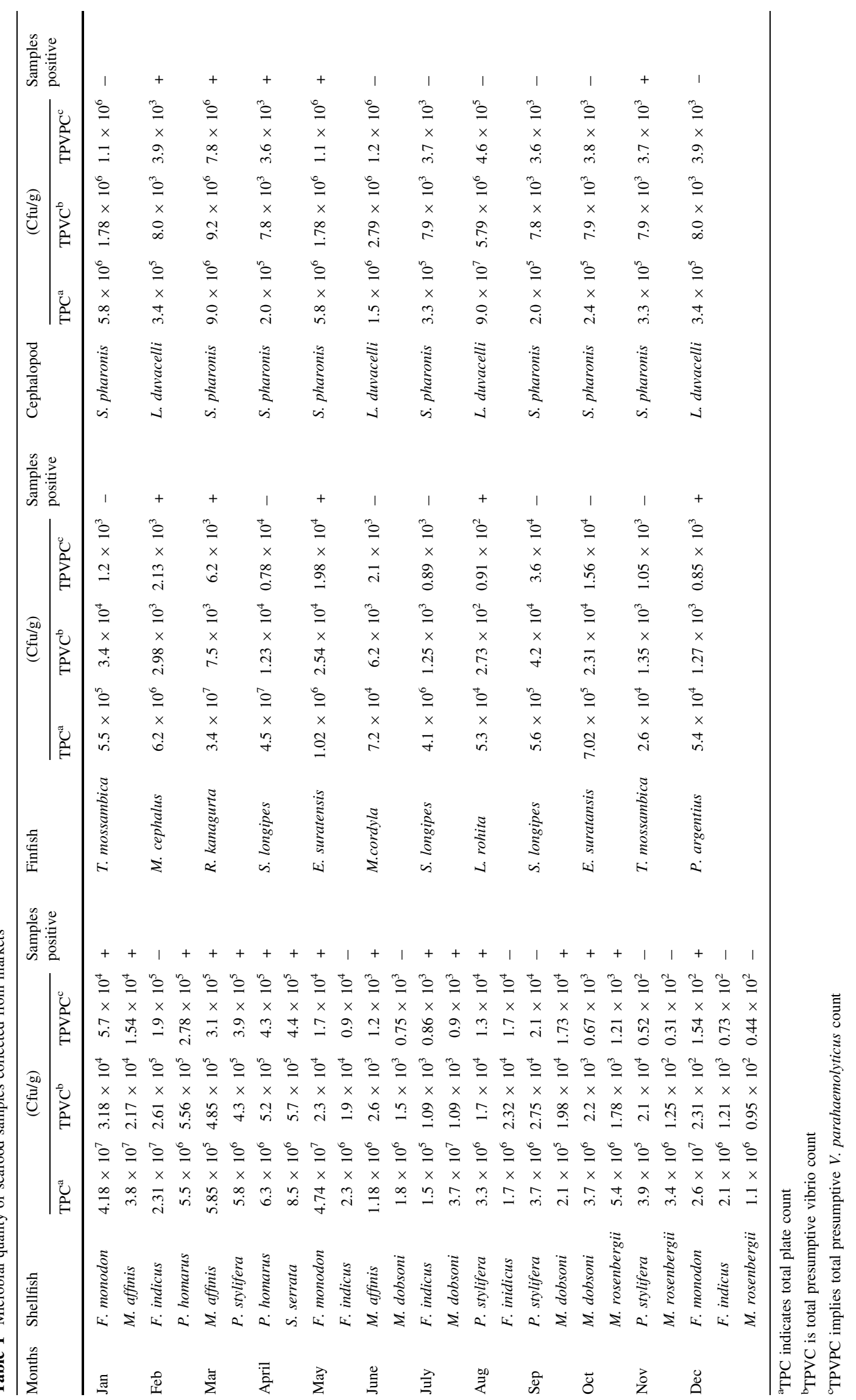




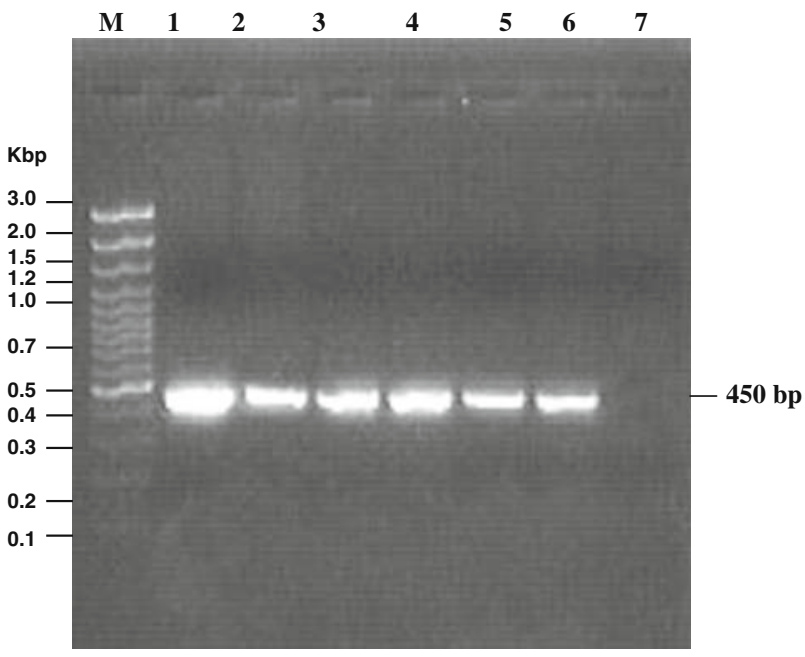

Fig. 1 PCR for the detection of $t l$ gene (450 bp). Lane M: DNA ladder (100 bp); Lanes 1: MTCC 451 (type strain); Lanes 1-2: $V$. parahaemolyticus isolates from finfish, lane 3-4 isolates from shrimp, lane 5-6 isolates from cephalopod samples containing $t l$ gene, lane 7: PCR negative control

index), which in turn forms the major cluster (60\% isolates) having included the isolates from fish and cephalopod samples. Group B was further sub-clustered into two groups, namely B1 (24\% isolates) and B2 (36\% isolates). $\mathrm{B} 1$ clustered with $\mathrm{B} 2$ at $\mathrm{S} \leq 30 \%$. A distinct grouping between clusters was apparent pertaining to the source of isolation, while no such groups were found pertaining to seasonality of samples. $V$. parahaemolyticus positive control (MTCC 451) was found to be grouped with cluster A,

Table 2 Antibiotic resistance pattern of $V$. parahaemolyticus isolates

\begin{tabular}{lccc}
\hline Antibiotics & $\mathrm{S} \%^{\mathrm{a}}$ & $\mathrm{I} \%^{\mathrm{b}}$ & $\mathrm{R} \%^{\mathrm{c}}$ \\
\hline Ampicillin & 9.5 & 9.5 & 80.9 \\
Polymixin-B & 4.7 & 4.7 & 90.4 \\
Streptomycin & 14.3 & 9.5 & 76.2 \\
Kanamycin & 19.1 & 9.5 & 71.5 \\
Gentamycin & 38.1 & 52.3 & 9.5 \\
Neomycin & - & 47.6 & 52.3 \\
Chlorotetracycline & - & 14.3 & 85.7 \\
Oxytetracycline & 76.2 & 23.8 & - \\
Tetracycline & 100 & - & - \\
Nalidixic acid & 100 & - & - \\
Chloramphenicol & 85.7 & 9.5 & 4.7 \\
Cephalexin & 4.7 & 19 & 76.2 \\
Nitrofurantoin & 85.7 & 14.3 & \\
Furazolidone & 71.4 & 23.8 & 4.7 \\
Trimethoprim & 90.5 & 4.7 & 4.7 \\
\hline
\end{tabular}

\footnotetext{
${ }^{a}$ S-sensitivity

${ }^{b}$ I-intermediary sensitivity

${ }^{\mathrm{c}} \mathrm{R}$-resistance to the antibiotics
}

which forms the major cluster. Urease positive $V$. parahaemolyticus (NCMB 1902) served as a control for urease activity clustered with the urease positive isolate. This urease positive isolate was recovered from $M$. dobsoni sample and was grouped in the same sub-cluster B1. The gel pattern revealed $8-10$ bands ranging from 0.45 to $3.0 \mathrm{~kb}$ (Fig. 2). The characteristic fingerprint patterns

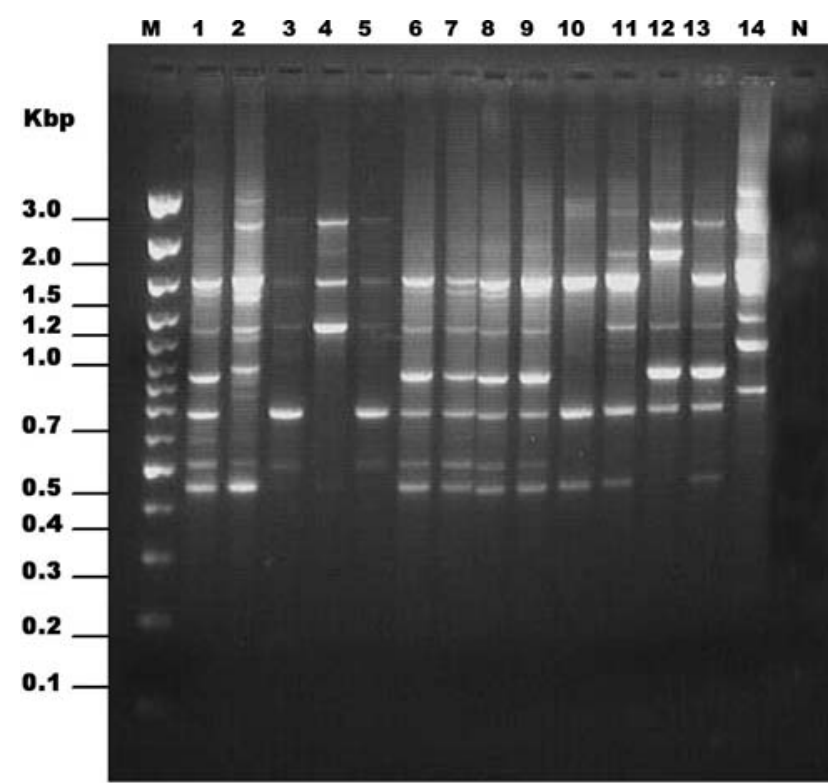

Panel A

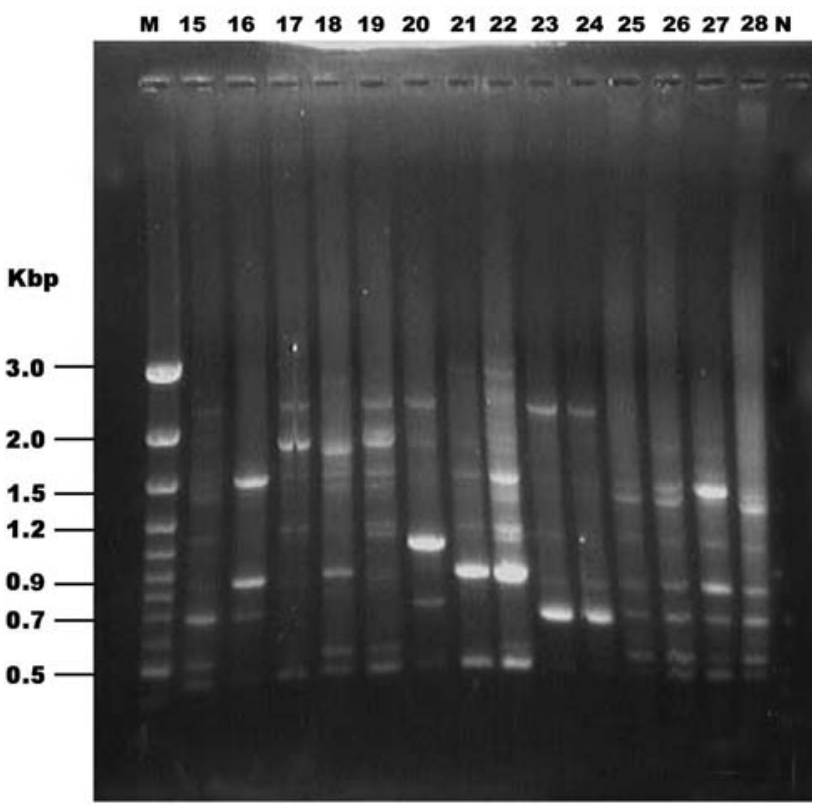

Panel B

Fig. 2 RAPD-PCR profiles of $V$. parahaemolyticus strains isolated from market samples. Lane M: DNA ladder (100 bp); Lane N: PCR negative control; Panel A: lane 1-9: isolates from finfish samples, lane 10-13 and lane 15-19: isolates from shellfish samples, lane 20-27 in Panel B contain isolates from cephalopod samples, lane 14 contain $V$. parhaemolyticus type strain (NCMB 1902), lane 28 contain V. parahaemolyticus type strian (MTCC 451) 
Fig. 3 Dendrogram illustrating the clustering of RAPD profile of $V$. parahaemolyticus isolates from market samples. Bars are shown at each node, corresponding to the standard deviation values in that region of the similarity matrix. The average and the standard deviation of similarity values for the selected nodes and similarity scale are shown above the dendrogram

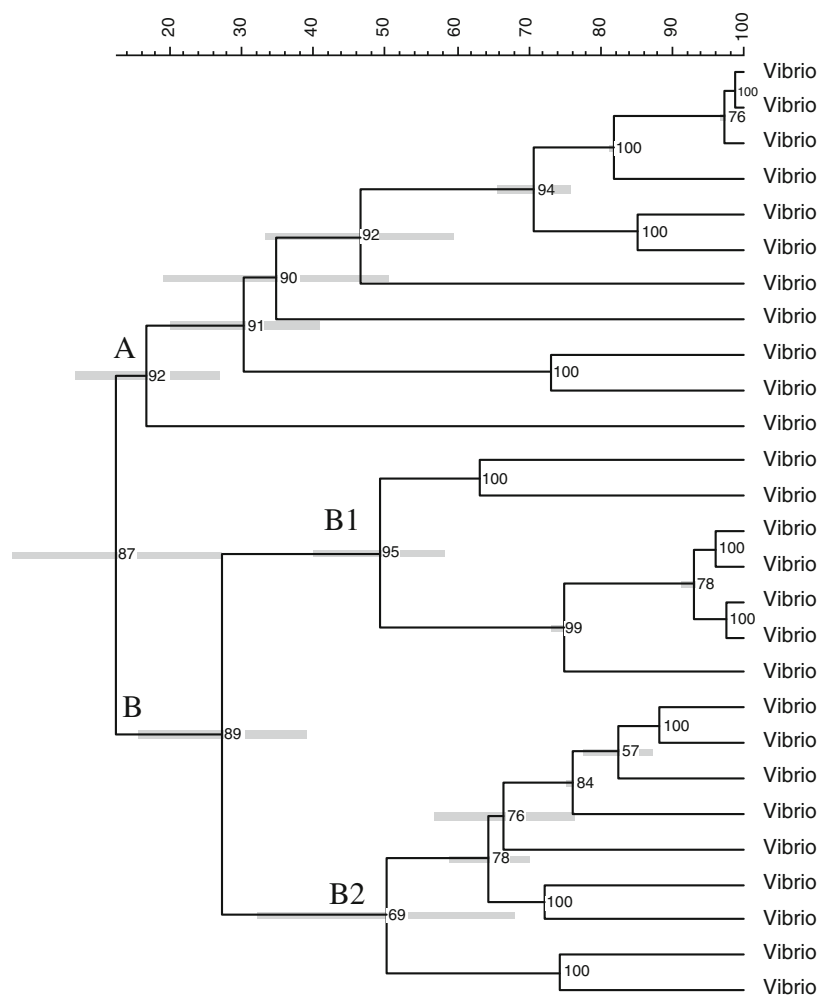

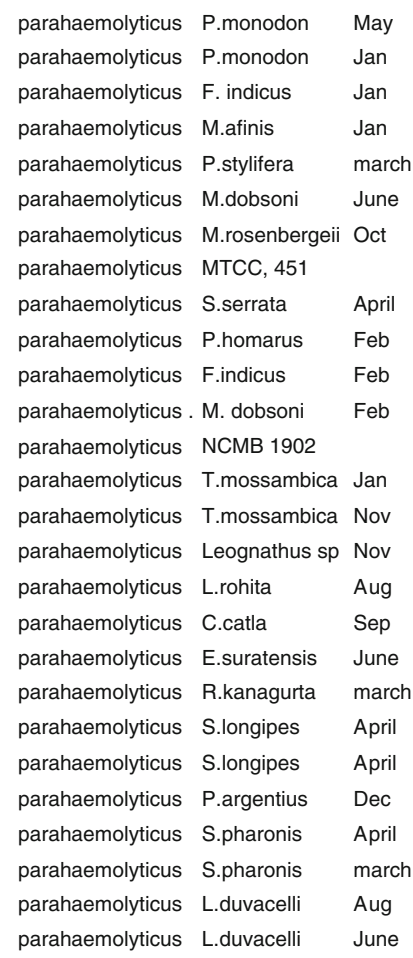

parahaemolyticus P.monodon May parahaemolyticus P.monodon Jan parahaemolyticus $F$. indicus Jan parahaemolyticus M.afinis Jan parahaemolyticus P.stylifera march parahaemolyticus M.dobsoni June parahaemolyticus M.rosenbergeii Oct parahaemolyticus MTCC, 451 parahaemolyticus S.serrata April parahaemolyticus P.homarus Feb parahaemolyticus F.indicus Feb parahaemolyticus. M. dobsoni Feb parahaemolyticus NCMB 1902 parahaemolyticus T.mossambica Jan parahaemolyticus T.mossambica Nov parahaemolyticus Leognathus sp Nov parahaemolyticus L.rohita Aug parahaemolyticus C.catla Sep parahaemolyticus E.suratensis June parahaemolyticus R.kanagurta march parahaemolyticus S.longipes April parahaemolyticus S.longipes April parahaemolyticus P.argentius Dec parahaemolyticus S.pharonis April parahaemolyticus L.duvacelli Aug parahaemolyticus L.duvacelli June obtained with primers are shown as dendrogram and gel pictures (Fig. 3).

\section{Discussion}

The members of the genus Vibrio have been frequently defined as opportunistic and potential pathogenic bacteria of the water bodies especially in tropical waters (Huss 1997), and in India the incidence of $V$. parahaemolyticus has reported to be doubled in the last 5 years (Chowdhury et al. 2000). V. parahaemolyticus is an important seafood borne pathogen, and therefore detection of this organism in seafoods is essential.

In this study $81 \%$ of the seafood samples analyzed exceeded the limit specified for TPC (USFDA 2001) ranging from $5.5 \times 10^{5}$ to $9.0 \times 10^{7} \mathrm{cfu} / \mathrm{g}$, the higher counts were found in the cephalopod samples (Table 1). TPVPC was found to cross the specified limit in $71 \%$ of the samples (ICMSF 1986). The possible reason for the higher bacterial and presumptive $V$. parahaemolyticus counts in cephalopod samples can be attributed to the depth zone (150-200 m) from which they were caught. Benthic zone is known to harbor higher microbial communities but lower counts of $V$. parahaemolyticus, which is mainly encountered in the surface seawaters (Tsukamoto et al. 1993). The present study revealed $67 \%$ of finfish samples collected from Cochin markets were of poor quality considering the
TPC limits set by the USFDA, EU, and Export Inspection Council of India $\left(10^{5} \mathrm{cfu} / \mathrm{g}\right)$. It was apparent that quality of fish sold in domestic markets was poor. Nambiar and Iyer (1990) and Nambiar and Surendran (2003) have made a detailed investigation on the microbial quality of seafood samples sold in the retail markets of Cochin, and their results revealed $72 \%$ of the samples sold in the retail markets of Cochin were of poor quality based on TPC levels, which exceeded $10^{7} \mathrm{cfu} / \mathrm{g}$. These counts were found to be comparatively higher than that reported in the present study. This clearly indicates improvement in the quality of samples marketed from this area over time period due to the implementation of stringent practices viz., Hazard Analysis Critical Control Point (HACCP), Standard Sanitation Operating Procedures (SSOP). Lakshmanan et al. (1993) reported higher bacterial counts in processed squid and cuttlefish as compared to its whole products apparently due to human handling.

The results of this study revealed the incidence of $V$. parahaemolyticus in $55 \%$ of the samples. Notably, incidence rates differed with respect to the kind of sample, highest being found in the shellfish samples (64\%) followed by finfish (42\%), and cephalopods (40\%). The higher incidence in shrimps can be correlated with the ability of this bacterium to utilize chitin, which is abundantly available in the crustaceans. Moreover shrimps are rich in free amino acid content, which serves as an excellent growth medium for the proliferation of this bacterium. 
Several authors reported the incidence of $V$. parahaemolyticus from various markets located in southwest coast of India (Bandekar et al. 1982; Karunasagar et al. 1984). Sanjeev and Stephen (1993) reported about $72 \%$ incidence of $V$. parahaemolyticus from different species of shrimps marketed from this area. Anand et al. (2002) reported higher bacterial load in shrimps $\left(1 \times 10^{4}-1.21 \times 10^{8} \mathrm{cfu} / \mathrm{g}\right)$ from the markets of southeast coast of India. Distribution of vibrios can be attributed to the suspended particulate matter of the water column, and is further influenced by various limiting factors like salinity, $\mathrm{pH}$, depth of water column, tidal cycle, and/or unidentified biological factors. In the present study incidence of $V$. parahaemolyticus was found throughout the sampling period, highest being apparent during the summer months, presumably due to the higher salinities prevailing in those periods.

Incidence of $V$. parahaemolyticus was above $10^{3} \mathrm{cfu} / \mathrm{g}$ in $42 \%$ of the finfish samples. This high count of $V$. parahaemolyticus in particular in finfish samples could be due to the sampling strategy followed in the present study. In brief, meat was picked from different parts of fish sample viz., skin, intestine and gills, and subjected to microbiological analysis as a whole. The intestinal contents of finfish serves as a good reservoir for vibrios apparently due to the higher nutrient content of the intestine, and the capacity of the bacterium to withstand substantially low $\mathrm{pH}$ in stomach.

A series of biochemical tests and molecular approach like $t l$-targeted PCR was used (Bej et al. 1999) for the identification of this pathogen. All the biochemically confirmed isolates were found to possess species-specific $t l$ gene. The results of this study indicated that the $t l$-targeted PCR method is sensitive and rapid in detecting $V$. parahaemolyticus. However, the biochemical determination and identification of environmental Vibrio species has been problematic, time consuming, and often confusing due to their great diversity (Alsina and Blanch 1994). RAPD-PCR generated fingerprinting has been successfully used in this study to discriminate the widely diverse bacterial populations. RAPD analysis revealed two major clusters, namely group A and B. The former included all the cultures isolated from crustaceans, while the latter comprised of fish and cephalopod isolates. The clustering of urease positive control with urease positive isolate into a distinct group B1 reveals their specific identity. In cluster B2 isolates from fish and cephalopods were grouped together thus indicating their genetic similarity. The cultures isolated from cephalopod samples exhibited more similarity to the cultures isolated from finfish rather than crustaceans.

Although $10 \%$ of the isolates exhibited weak haemolysis, none of them were found to exhibit $\beta$-haemolysis on Wagatsuma agar. This weak haemolysis points towards the presence of virulence factors other than TDH/TRH. The capability of the strains to produce few extracellular enzymes may also lead to the weak haemolysis (Lee et al. 2002). In contrast Sanjeev (1999) and Sudha et al. (2002) reported higher Kanagawa positives from environmental strains of Cochin. Few authors have even correlated the KP with the positive detection of urease by urea hydrolysis (Kaysner et al. 1994; Iida et al. 1998). However, in the present study none of the weak haemolytic strains were found to exhibit urease activity. Athough about $1 \%$ of the isolates were found to exhibit urease activity, the potential risk involved in consuming such seafoods cannot be ignored due to its short generation time.

Drug resistance in environmental and clinical isolates of V. cholerae is well known (Vijayalakshmi et al. 1997). In 2001 residues of antibiotics emerged as a major concern for fish and fishery products exported to EU and United States. Antibiotics such as chloramphenicol and nitrofurans have been set at the limit of determination. In recent years, there has been an increase in the clinical importance of non-cholerae vibrios, but little is known about their antibiotic susceptibility. The occurrence of MAR among the bacterial species could be a problem associated with transfer or resistance to other organisms of human/veterinary significance (Kasper et al. 1990). In the present study MAR index was found to be 0.4 indicating the higher resistance acquired by the isolates. This study presents the sensitivity of the $V$. parahaemolyticus isolates from this area towards life saving drugs, viz., tetracycline, nalidixic acid followed by chloramphenicol, trimethoprim, nitrofurantoin thus indicating the safety of seafood products. However, few number of isolates exhibited resistance towards gentamycin. The significance of MAR in different ecosystem was also studied by Kaspar et al. (1990), and the results of the present study are in agreement with their study.

In conclusion, the study revealed detection of this pathogen by PCR using species specific, $t l$ gene was found to be rapid and sensitive. This study demonstrated the incidence of $V$. parahaemolyticus in more than $50 \%$ of the samples marketed with a value of 0.4 as MAR index suggesting environmental significance. RAPD-PCR generated fingerprints has been successfully used to discriminate diverse bacterial populations. Although the incidence of urease positive and haemolytic strains was meager the risk involved in consuming such seafoods cannot be ignored due to its short generation time. However, the incidence of $V$. parahaemolyticus isolates sensitive to life saving drugs indicates the safety of the seafood products marketed from Cochin.

Acknowledgements The authors are grateful to Dr. K. Devadasan, Director, Central Institute of Fisheries Technology, Cochin and Prof. (Dr.) Mohan Joseph Modayil, Director, Central Marine Fisheries Resarch Institute for providing necessary facilities and encouragement 
for carrying out the study. The guidance and support rendered by Dr. Nirmala Thampuran, Head of the Mircrobiology Fermentation Biotechnology Division, Central Institute of Fisheries Technology, Cochin, to carry out this work is gratefully acknowledged.

\section{References}

Alsina M, Blanch AR (1994) A set of keys for biochemical identification of environmental Vibrio species. J Appl Bacteriol 74:79-85

Anand C, Jeyasekaran G, Jeya Shakila R, Edwin S (2002) Bacteriological quality of seafood landed in Tuticorin fishing harbour. J Food Sci Technol 39:694-697

Andrews WH, Hammack TS (2001) Salmonella. In: Bacteriological analytical manual Online, Chapter 5 (2001), 9th edn. US FDA Center for Food Safety and Applied Nutrition. Available at: http:// vm.cfsan.fda.gov/_ebam/bam-toc.html

Ausubel FM, Brent R, Kingston RE, Moore DD, Sideman J, Smith J, Struhl K (1987) Current protocols in molecular biology. Wiley, New York

Bandekar JR, Chander R, Nerkar DP, Lewis NF (1982) Occurence of Kanagawa-positive Vibrio parahaemolyticus strains in shrimp (Penaeus Indicus). Indian Journal of Microbiology 22:247-248

Barza M (2002) Potential mechanisms of increased disease in humans from antimicrobial resistance in food animals. Clin Infect Dis 34(3): 123-125

Bauer AW, Kirby WMM, Sherris JC, Turck M (1966) Antibiotic susceptibility testing by a standardized single disk method. Am J Clin Pathol 45:493-496

Bej AK, Patterson DP, Brasher CW, Vickery MCL, Jones DD, Kaysner CA (1999) Detection of total and haemolysin-producing Vibrio parahaemolyticus in shellfish using multiplex PCR amplification of $t l, t d h$ and $t r h$. J Microbiol Methods 36:215-225

Chowdhury NR, Chakraborty S, Ramamurthy T, Nishibuchi M, Yamasaki S, Takeda Y, Nair GB (2000) Molecular evidence of clonal Vibrio parahaemolyticus pandemic strains. Emerg Infect Dis 6:631-636

Delgado CL, Wada N, Rosegrant MW, Meijer S, Ahmed M (2003) Fish to 2020 supply and demand in changing global markets. International Food Policy Research Institute, Washington, DC

Elliot EL, Kaysner CA, Tamplin ML (1992) Appendix 3. Media and reagents. In: USFDA bacteriological analytical manual, 7th edn. AOAC International, Arlington, Va. p 508

Fujino T, Okuno Y, Nakada D, Aoyama A, Fukai K, Mukai T, Ueho T (1953) On the bacteriological examination of shirasu food poisoning. Med J Osaka Univ 4:299-304

Hervio-Heath D, Colwell RR, Derrien A, Robert-Pillot A, Fournier JM, Pommepuy M (2002) Occurrence of pathogenic vibrios in coastal areas of France. J Appl Microbiol 92:1123-1135

Hulton CSJ, Higgins CP, Sharp PM (1991) ERIC sequences: a novel family of repetitive elements in the genomes of Escherichia coli, Salmonella typhimurium and other enterobacteria. Mol Microbiol 5:825-834

Huss H (1997) Control of indigenous pathogenic bacteria in seafood. Food Control 8:91-98

ICMSF (1986) Microorganisms in foods 2, sampling for microbiological analysis: principles and specific applications, 2nd edn. University of Toronto Press, Buffalo, NY

Iida T, Park KS, Suthienkul O, Kozawa J, Yamaichi Y, Yamamoto K, Honda T (1998) Close proximity of the $t d h, t r h$ and ure genes on the chromosome of Vibrio parahaemolyticus. Microbiology 144:2517-2523

Kaneko T, Colwell RR (1975) Adsorption of Vibrio parahaemolyticus onto chitin and copepods. Appl Microbiol 29:269
Karunasagar I, Venugopal MN, Karunasagar I (1984) Levels of Vibrio parahaemolyticus in Indian shrimp undergoing processing for export. Can J Microbiol 30:713-715

Karunasagar I, Sugumar G, Karunasagar I, Reilly PJA (1996) Rapid polymerase chain reaction method for detection of Kanagawa positive Vibrio parahaemolyticus in seafoods. Int $\mathrm{J}$ Food Microbiol 31:317-323

Kaspar CW, Burgess JL, Knight IT, Colwell RR (1990) Antibiotic resistance indexing of Escherichia coli to identify the sources of faecal contamination in water. Can J Microbiol 36:891-894

Kaysner CA, Abeyta C, Jr.Trost PA, Wetherington JH, Jinneman KC, Hill WE, Wekell MM (1994) Urea hydrolysis can predict the potential pathogenicity of Vibrio parahaemolyticus strains isolated in the Pacific Northwest. Appl Environ Microbiol 60:3020-3022

Lakshmanan PT, Varma PRG, Iyer TSG (1993) Quality of commercially frozen cephalopod products from India. Food Control 43:159-164

Lee KK, Liu PC, Chen YC, Huang CY (2001) The implication of ambient temperature with outbreak of vibriosis in cultured small abalone, Haliotis diversicolor supertexta Lischke. J Therm Biol 26:585-587

Lee CY, Cheng MF, Yu MS, Pan MJ (2002) Purification and characterization of a putative virulence factor, serine protease, from Vibrio parahaemolyticus. FEMS Microbiol Lett 209:31-37

Nambiar VN, Iyer KM (1990) Microbial quality of fish in retail trade in Cochin. Fishery Technol 27:51-59

Nambiar VN, Surendran PK (2003) Microbial hazards in fish sold in the retail markets of Cochin. In: Surendran PK, Mathew PT, Thampuran N, Nambiar VN, Joseph J, Boopendranath MR, Lakshmanan PT, Nair PGV (eds) Seafod safety. Society of Fisheries Technologists, (India) Cochin, pp 491-496

Oakey HJ, Gibson LF, George AM (1998) Co-migration of RAPDPCR amplicons from Aeromonas hydrophila. FEMS Microbiol Lett 164:35-38

Okuda J, Ishibashi M, Hayakawa E, Nishino T, Takeda Y, Mukhopadhyay AK, Garg S, Bhattacharya SK, Nair GB, Nishibuchi M (1997) Emergence of a unique O3:K6 clone of Vibrio parahaemolyticus in Calcutta, India, and isolation of strains from the same clonal group from Southeast Asian travelers arriving in Japan. J Clin Microbiol 35:3150-3155

Sanjeev S (1999) Incidence, Enteropathogenicity and Antibiotic sensitivity of Vibrio parahaemolyticus from brackish water culture pond. Fishery Technol 36:13-18

Sanjeev S, Stephen J (1992) Antibiotic sensitivity of Kanagawa positive and Kanagawa-negative strains of Vibrio parahaemolyticus isolated from fishes marketed in Kochi. Fishery Technol 29:162-165

Sanjeev S, Stephen J (1993) Incidence of Vibrio parahaemolyticus in fish and shellfish marketed in Cochin. Indian J Mar Sci 22(1):7071

Sneath PHA, Sokal RR (1973) Numerical taxonomy. Freeman, San Francisco, CA

Sudha K, Thampuran N, Surendran PK (2002) Ecology and distribution of Vibrio parahaemolyticus from fish and fishery environs. Paper presented in the symposium Seafood safetystatus and strategies conducted by society of fisheries technologist, India (SOFTI) and CIFT (2002), pp 28-30

Taniguchi H, Hirano H, Kubomura S, Higashi K, Mizuguchi Y (1986) Comparison of the nucleotide sequences of the genes for the thermostable direct hemolysin and the thermolabile hemolysin from Vibrio parahaemolyticus. Microb Pathog 1:425-432

Tsukamoto KK, Oyaizu H, Nanba K, Simidu U (1993) Phylogenic relationship of marine bacteria, mainly members of the family Vibrionaceae, determined on the basis of 16S rRNA sequences. Int J Syst Bacteriol 43:8-19 
USFDA (2001) Bacteriological analytical manual, 8th edn. (revised), Association of Official Analytical Chemists, Washington DC

Vijayalakshmi N, Rao RS, Badrinath S (1997) Minimum inhibitory concentration (MIC) of some antibiotics against Vibrio cholerae 0139 isolates from Pondicherry. Epidemiol Infect 119:25-28

Wagatsuma S (1968) A medium for the test of the hemolytic activity of Vibrio parahaemolyticus. Media Circle 13:159-162

Wong HC (2003) Detecting and molecular typing of Vibrio parahaemolyticus. J FDA 11:79-86

Wong HC, Lu KT, Pan TM, Lee CL, Shih DYC (1996) Subspecies typing of Vibrio parahaemolyticus by pulsed-field gel electrophoresis. J Clin Microbiol 34:1535-1539
Wong HC, Ho CY, Kuo LP, Pan TM, Wang TK, Shih DYC (1999a) Ribotyping of Vibrio parahaemolyticus isolates obtained from food poisoning outbreaks in Taiwan. Microbiol Immunol 43:631-636

Wong HC, Liu CC, Pan TM, Wang TK, Shih DYC (1999b) Molecular typing of Vibrio parahaemolyticus isolates obtained from food poisoning outbreaks in Taiwan by random amplified polymorphic DNA analysis. J Clin Microbiol 37:1809-1812

Wong HC, Liu SH, Wang TK, Lee CL, Chiou CS, Liu DP, Nishibuchi M, Lee BK (2000) Characterization of Vibrio parahaemolyticus O3:K6 from Asia. Appl Environ Microbiol 66:3981-3986 